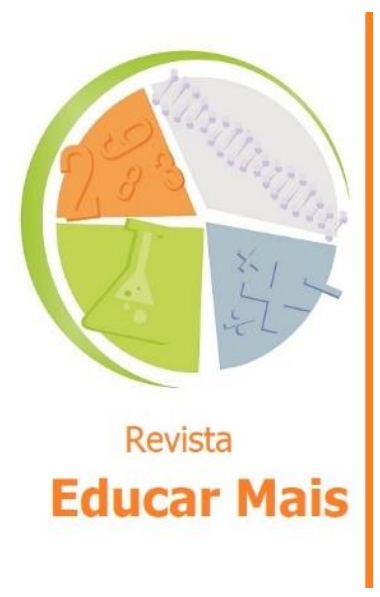

\title{
Culto ao corpo e suas formas de disseminação através das mídias: uma revisão integrativa no olhar da Educação Física
}

\author{
Cult of the body and its forms of dissemination through the media: an \\ integrative review in the perspective of Physical Education
}
El culto corporal y sus formas de difusión a través de los medios de comunicación: una revisión integrativa en la vista de la Educación Tísica

Mara Dantas Pereira ${ }^{1}$; Mariana Pícaro Cerigatto²

\begin{abstract}
RESUMO
Este trabalho teve como objetivo realizar uma análise da produção científica sobre a influência da mídia acerca do culto ao corpo no olhar da Educação Física Escolar e Universitária. Trata-se de revisão integrativa da literatura, realizada por meio da busca por artigos científicos capturados nas principais bases de dados. Por meio dos estudos analisados, foi possível compreender a necessidade de romper as barreiras criadas pelo sistema hegemônico de culto ao corpo, que afeta especialmente os jovens. No contexto formativo e educacional é necessário atribuir ao currículo acadêmico dos professores e nas aulas de Educação Física as implicações dos conteúdos midiáticos nos padrões corporais, o que leva o professor a trabalhar além do aspecto biológico. Os docentes devem promover a criação de ferramentas e conteúdos que despertem nos alunos uma visão crítica diante do que é imposto pela mídia e a indústria da beleza no ideal de corpo. Conclui-se que o trabalho possibilitou trazer reflexões e um confronto de ideias em torno do influxo das mídias sobre os saberes de corpo de estudantes e professores.
\end{abstract}

Palavras-chave: Corpo; Educação Física; Mídia; Padronização.

\begin{abstract}
This work aimed to carry out an analysis of scientific production on the influence of the media on the cult of the body in the view of School and University Physical Education. This is an integrative literature review, carried out by searching for scientific articles captured in the main databases. Through the analyzed studies, it was possible to understand the need to break the barriers created by the hegemonic system of cult of the body, which especially affects young people. In the formative and educational context, it is necessary to attribute to the academic curriculum of teachers and in Physical Education classes the implications of media content on body standards, which leads the teacher to work beyond the biological aspect. Teachers should promote the creation of tools and content that awaken a critical view of students in face of what is imposed by the media and the beauty industry on the ideal of the body. It is concluded that the work made it possible to bring reflections and a confrontation of ideas around the influence of the media on the knowledge of the body of students and teachers.
\end{abstract}

Keywords: Body; Physical Education; Media; Standardization.

\footnotetext{
${ }^{1}$ Graduada em Psicologia. Membro do Grupo de Pesquisa Educação, Tecnologias e Contemporaneidade (GPETEC) da Universidade Tiradentes (UNIT) e do Grupo de Pesquisa Educação, Cultura e Subjetividade (GPECS) da Universidade Federal de Sergipe (UFS), Sergipe/SE - Brasil. E-mail: maradantaspereira@gmail.com

2 Doutora em Ciência da Informação e docente do Programa de Pós-Graduação em Educação (PPED) da Universidade Tiradentes (UNIT), Sergipe/SE - Brasil. E-mail: mariana.picaro@souunit.com.br
} 


\section{RESUMEN}

Este trabajo tuvo como objetivo realizar un análisis de la producción científica sobre la influencia de los medios de comunicación en el culto al cuerpo desde la perspectiva de la Educación Física Escolar y Universitaria. Se trata de una revisión integradora de la literatura, realizada mediante la búsqueda de artículos científicos capturados en las principales bases de datos. A través de los estudios analizados se pudo comprender la necesidad de romper las barreras creadas por el sistema hegemónico de culto al cuerpo, que afecta especialmente a los jóvenes. En el contexto formativo y educativo, es necesario atribuir al currículo académico de los docentes y en las clases de Educación Física las implicaciones de los contenidos mediáticos en los estándares corporales, lo que lleva al docente a trabajar más allá del aspecto biológico. Los docentes deben promover la creación de herramientas y contenidos que despierten una mirada crítica en los estudiantes frente a lo que los medios de comunicación y la industria de la belleza imponen sobre el ideal del cuerpo. Se concluye que el trabajo permitió traer reflexiones y un enfrentamiento de ideas en torno a la influencia de los medios de comunicación en el conocimiento del cuerpo de estudiantes y docentes.

Palabras clave: Cuerpo; Educación Física; Medios de comunicación; Estandarización.

\section{INTRODUÇÃO}

Parte do que é disseminado pela mídia passa a ser também tema de discussões nos espaços escolares, visto que os jovens e adolescentes são um dos principais públicos-alvo de vendas e marketing promovidos por ela, afinal a sociedade no momento atual está tracejada em uma relação de consumismo que evidencia a exploração do corpo para "sempre jovem". Segundo Silva, Santos e Mezzaroba (2013), a mídia pode ser definida como espaço de possibilidades e de realidade material pré-existente a qualquer conhecimento e a qualquer prática a que será objeto. Para Thebaldi (2020), a mídia tem uma grande parcela de responsabilidade na distorção dos conceitos de "corpo belo" e "corpo não belo", reforçando narcisismo contemporâneo, onde tudo se encontra à venda, basta querer e poder.

Fundamentados nesse princípio, cabe destacar, que as mídias, como a televisão, e a internet, também participam diretamente na formação do jovem, sugerindo, estimulando e delineando determinadas formas de existência coletiva ou da relação consigo mesmo e com o outro. Nesse âmbito, inseremse também as mídias sociais que são caracterizadas como uma subdivisão de mídia, tendo diversos meios como: e-mail, blogs, sites e aplicativos de redes sociais (Instagram, Facebook, WhatsApp, etc.) (GUEDES JUNIOR, 2020).

Diante de tais contemplações, é de suma importância despertar a curiosidade dos professores para a constituição dos modos de ser adolescente estudante em meio às influências de regras sociais disseminadas em veículos midiáticos (THEBALDI, 2020). A partir dessa premissa, é possível compreender que a escola é um ambiente de realização de tais problematizações, visto que, possui como um dos principais propósitos a conscientização dos estudantes, para que estes possam se tornarem indivíduos críticos sobre os mais diversos assuntos, tais como, os ideais de corpo.

De acordo com Santos e Costa (2018), é notável o empenho em envolver temáticas de corpo e estereótipos no contexto educacional, que começou a ganhar força a partir dos Parâmetros Curriculares Nacionais - PCN's (1998) - documento oficial norteador das políticas curriculares brasileiras para o Ensino Fundamental e Médio-. A partir desses PCN's, foi possível identificar abordagens pedagógicas de intervenção para tratar os estereótipos corporais, com a defesa da realização de aulas mistas de Educação Física, a fim de que os estudantes aprendessem a não discriminar e a compreender as diferenças entre os corpos. 
Contudo, essa forma apresentada pelos PCN's se tornou ainda mais robusta, ao reconhecer a influência das mídias sobre o corpo. Nos mesmos moldes, a Base Nacional Comum Curricular - BNCC (BRASIL, 2017) se apresenta como um importante e atual documento de caráter normativo que define o conjunto orgânico e progressivo de aprendizagens essenciais para os estudantes ao longo das etapas da Educação Básica. A BNCC estabelece competências específicas para a Educação Física no ensino fundamental, e enfatiza a capacidade dos estudantes de "identificar a multiplicidade de padrões de desempenho, saúde, beleza e estética corporal, analisando, criticamente, os modelos disseminados na mídia e discutir posturas consumistas e preconceituosas"' (BRASIL, 2017, p. 223).

Nesse contexto, é relevante citar a CNE/CES No 6, de 18 de dezembro de 2018 que institui as Diretrizes Curriculares Nacionais dos Cursos de Graduação em Educação Física. Diante desse documento, podemos destacar o Art. $3^{\circ}$, por mais que não destaque diretamente a necessidade de discutir corpo e padrões de corpo neste nível de ensino, contempla que o profissional de licenciatura de Educação Física deve dominar conhecimentos específicos, dentre eles os padrões e valores estéticos, como demonstrado no trecho a seguir:

[...] dominar os conhecimentos conceituais, procedimentais e atitudinais específicos da Educação Física e aqueles advindos das ciências afins, orientados por valores sociais, morais, éticos e estéticos próprios de uma sociedade plural e democrática (BRASIL, 2018, p. 7).

Nesse cenário, a Educação Física tem a possibilidade de intervir, direta ou indiretamente, na cultura corporal dos estudantes, não apenas como disciplina curricular, mas também como prática social. Segundo Assaritti e Daolio (2011) é de suma importância que o docente de Educação Física em formação detenha em seus conhecimentos formativos o propósito de desenvolver a autonomia corporal de seus futuros alunos, ressignificando a prática das atividades desenvolvidas, e assim promover a uma reflexão sobre a realidade em que vivem, englobando a existência de um padrão corporal responsável pela possível insatisfação por parte deles diante de seus corpos.

Considerando essa visão de área, cabe ao professor de Educação Física manter-se atento a fatores externos que possam exercer influência em seus alunos e consequentemente, em suas aulas (ASSARITTI; DAOLIO, 2011; BISCARO; SILVA, 2016). Cabe mencionarmos ainda, que essas discussões que envolvem corpo, estereótipos, mídias e aulas de Educação Física escolar são cada vez mais necessárias e urgentes, visto que, nos últimos anos está havendo a ampliação do uso das mídias em rede, que vêm produzindo, reproduzindo e atualizando representações sobre gênero. As representações de corpos nas mídias sociais se apresentam como discursos espontâneos, "naturalizados" e largamente aceitos, mas são, acima de tudo, textos ou imagens especialmente construídas que revelam as nossas relações com a sociedade e com o que a sociedade representa (DIONISIO, 2005).

E ainda:

[..] a centralidade das mídias na vida das pessoas e a intensidade com que esses aparatos envolvem nosso cotidiano potencializam o poder de influência. $O$ que esses meios fazem é organizar mensagens que mostrem algum aspecto que desperte nosso interesse, porque nós, de alguma forma, nos reconhecemos naquele discurso ou desejamos adotá-lo como parte de nós mesmos (SIQUEIRA, 2014, p.64).

Assim, atrelar a discussão de representações da mídia sobre o corpo e a saúde nas aulas de Educação Física reforça objetivos da área de estudo denominada media literacy, ou então letramento midiático/mídia-educação, que se apresenta como uma área interdisciplinar que enfatiza não só a 
criação de conteúdo midiático nas escolas com a valorização do protagonismo dos alunos, mas a leitura crítica de conteúdos disseminados pelas mais diversas mídias e tecnologias (SIQUEIRA, 2014). Convém ainda ressaltar que não se deve compreender a mídia-Educação apenas dentro do viés de uso instrumental das mídias em sala de aula, sem promover a apropriação crítica e reflexiva de seus conteúdos (FANTIN, 2014).

Desde 1984, a Organização das Nações Unidas para a Educação, Ciência e Cultura (Unesco) reconhece a mídia-educação como área de estudo. E por mais que não haja uma disciplina específica no currículo da Educação Básica sobre letramento midiático, a BNCC (BRASIL, 2017) sublinha a necessidade de se inserir a cultura midiática e as linguagens midiáticas em todas as áreas disciplinares, inclusive na Educação Física, conforme já mencionado. Dentre as unidades temáticas e objetos de conhecimento propostos na BNCC para Educação Física, estão atividades que envolvem a habilidade de "discutir as transformações históricas dos padrões de desempenho, saúde e beleza, considerando a forma como são apresentados nos diferentes meios (científico, midiático, etc.)" (BRASIL, 2017, p. 239).

Portanto, a Educação Física escolar reforça-se nesta discussão, pois seu conteúdo nas aulas oportuniza incorporar questões ligadas ao corpo com intuito de problematizar os conhecimentos e vivências de seus alunos no que tange ao atual cenário somático. Nesse sentido, pode-se pontuar que investigar o corpo no contexto escolar, a partir de estudos científicos que trazem o contexto e ponto de vista dos estudantes e de professores torna-se um campo extremamente frutífero.

Entende-se que a relevância dessa pesquisa se consolida na medida em que ainda há uma série de possibilidades de análise sobre o corpo por diversos campos de saberes, como a necessidade de analisar criticamente os discursos midiáticos no contexto educacional, para que se possa, pedagogicamente, oferecer condições, nas quais, os estudantes desvendem os interesses e valores veiculados pela mídia acerca da Educação Física.

Diante de tais reflexões, explicitamos que o objetivo do presente artigo é realizar uma análise da produção científica sobre a influência da mídia acerca do culto ao corpo no olhar da Educação Física Escolar e Universitária.

\section{METODOLOGIA}

O presente estudo possui natureza qualitativa, sendo uma pesquisa de nível exploratório, que tem "como principal finalidade desenvolver, esclarecer e modificar conceitos e ideias, tendo em vista a formulação de problemas mais precisos ou hipóteses pesquisáveis para estudos posteriores" (GIL, 2008, p. 27). O método da pesquisa foi delineado enquanto Revisão Integrativa da Literatura (RIL), realizada entre os meses de março a julho de 2020. De acordo com Broome (2000), uma RIL tem por finalidade agregar resultados de pesquisas de maneira sistemática sobre um determinado tema ou questão. Tal método possibilita compilar de forma sintética múltiplos estudos, com delineamento distinto, publicados em um determinado campo do conhecimento e produzir uma ampla análise sobre a literatura disposta, proporcionando o aprofundamento sobre o tema proposto, reduzindo incertezas e evidenciando lacunas.

Para a realização dessa RIL, foram efetuadas seis etapas de pesquisa, propostas por Galvão e Pereira (2014): (1) identificação do tema e seleção da questão de pesquisa; (2) estabelecimento dos critérios de elegibilidade; (3) identificação dos estudos nas bases científicas; (4) avaliação dos estudos 
selecionados e análise crítica; (5) categorização dos estudos; e (6) avaliação e interpretação dos resultados com apresentação dos dados na estrutura da revisão integrativa.

Os critérios utilizados para inclusão dos artigos na pesquisa foram: estudos relevantes e relacionados ao tema; artigos científicos publicados no idioma português; que apresentassem relatos ou intervenções sobre o corpo, estereótipo, mídia e Educação Física; estudos com abordagem qualitativa e quantitativa, e publicados nos últimos dez anos. Os critérios de exclusão estabelecidos foram: artigos de revisão, estudos publicados em idiomas distintos do português, artigos duplicados, publicações anteriores aos dez últimos anos e que não abordavam questões de corpo, estereótipo, mídia no contexto da Educação Física Escolar ou Universitária.

Foram definidas as seguintes fontes de informação para busca: Biblioteca Virtual em Saúde (BVS), Scientific Eletronic Library Online (SciELO) e Periódicos da Coordenação de Aperfeiçoamento de Pessoal de Nível Superior (CAPES). Foi utilizada na estratégia de busca a seguinte combinação de termos, entretermos e operadores booleanos: ("corpo" OR "culto ao corpo" OR "estereótipo" OR "corporeidade") AND ("mídia" OR "mídias sociais" OR "meios de comunicação") AND ("educação física" OR "aulas de educação física" OR "professores de educação física" OR "alunos de educação física").

As buscas nas bases de dados ocorreram no período de março a abril de 2020, realizadas por dois avaliadores de forma independente (MDP e MPC), que fizeram a primeira filtragem dos artigos com base na análise do título e do resumo. Seguidamente, ambos os avaliadores analisaram os textos selecionados e verificaram a duplicidade dos mesmos e, por fim, foram aplicados os critérios de exclusão.

Por conseguinte, foram identificados 98 artigos através das buscas nas bases de dados. 0 total de 52 artigos foram excluídos após a análise de títulos e resumos. Posteriormente, foi feita a leitura na íntegra de 46 artigos. Sendo assim, 40 publicações foram excluídas por não responderem aos critérios de elegibilidade, ou seja, por não estarem no idioma português, e por estarem fora do recorte temporal. Nesta etapa, foram excluídos os artigos que não eram de pesquisas originais, além daqueles que não se relacionavam com a temática estudada tampouco com a questão de pesquisa. A revisão final foi composta por 6 artigos.

Após a seleção final, realizou-se a análise temática dos artigos na íntegra. Dessa maneira, os 6 artigos selecionados foram analisados pelos avaliadores independentes, que preencheram uma ficha de leitura e resumo dos textos, com o intuito de selecionar as informações mais relevantes à revisão. Para extrair os dados dos artigos selecionados, foi necessário a utilização um método de coleta de dados. Foi utilizado a abordagem de Souza et al. (2010), que além de conceder a sucinta organização dos dados, propicia a comparação dos estudos em tópicos específicos. Com isso, tal procedimento utilizado, buscou identificar: (1) dados gerais dos artigos como título, ano, autor(es), periódico e local do estudo; (2) método de pesquisa, método de coleta de dados, participantes e instrumentos; (3) conteúdo dos artigos como objetivo do estudo, principais resultados, discussões e considerações. Por fim, após a coleta de dados, foi realizada a interpretação dos resultados.

\section{RESULTADOS}

Os estudos selecionados tiveram como população-alvo estudantes de ensino médio, professores e acadêmicos de Educação Física. A maioria dos estudos (4) foi publicado nos cinco últimos anos. 
Destes, 4 correspondem a estudo de abordagem qualitativa, 1 de abordagem quantitativa e 1 pesquisa-ação. Os estudos de abordagem qualitativa representaram a maioria, seguindo a perspectiva de comparação entre as vivências de estudantes e professores com demandas de corpo, mídia na Educação Física, a partir de estudos amplos.

Seguidamente, após terem sido determinados os artigos para análise, realizou-se uma leitura na íntegra dos artigos selecionados, posteriormente foram elaboradas duas tabelas, nas quais se identificaram algumas caraterísticas dos estudos. As informações gerais referentes aos artigos selecionados para o estudo, encontram-se sumarizadas nas Tabelas 1 e 2.

Tabela 1 - Caracterização dos estudos selecionados, segundo o código de identificação, título/ano, autor(es), periódico e local do estudo.

\begin{tabular}{|c|c|c|c|c|}
\hline Código & Título/ano & Autor(es) & Periódico & Local do estudo \\
\hline A1 & $\begin{array}{l}\text { Corpo e Educação Física } \\
\text { Escolar no ensino médio: a } \\
\text { visão dos alunos/2014 }\end{array}$ & Costa e Silva & $\begin{array}{l}\text { Revista Brasileira } \\
\text { de Ciências do } \\
\text { Esporte - RBCE }\end{array}$ & Rio de Janeiro \\
\hline A2 & $\begin{array}{c}\text { Corpo, mídia e Educação } \\
\text { Física/2016 }\end{array}$ & Biscaro e Silva & $\begin{array}{l}\text { Revista educação } \\
\text { pública (Rio de } \\
\text { Janeiro) }\end{array}$ & Paraná \\
\hline A3 & $\begin{array}{l}\text { Uso das redes sociais, } \\
\text { imagem corporal e } \\
\text { influência da mídia em } \\
\text { acadêmicos dos cursos de } \\
\text { Educação Física/2020 }\end{array}$ & $\begin{array}{l}\text { Santos e } \\
\text { Gonçalves }\end{array}$ & $\begin{array}{l}\text { Itinerarius } \\
\text { Reflectionis }\end{array}$ & Goiás \\
\hline A4 & $\begin{array}{l}\text { Construindo diálogos entre } \\
\text { a mídia - educação e à } \\
\text { educação física: uma } \\
\text { experiência na escola/2015 }\end{array}$ & Chaves et al. & Motrivivência & Rio Grande do Norte \\
\hline A5 & $\begin{array}{l}\text { A intervenção do professor } \\
\text { de Educação Física junto a } \\
\text { aluno do ensino médio } \\
\text { sobre o fenômeno do culto } \\
\text { ao corpo/2011 }\end{array}$ & Assaritti e Daólio & $\begin{array}{l}\text { Conexões: revista } \\
\text { da Faculdade de } \\
\text { Educação Física } \\
\text { da UNICAMP }\end{array}$ & São Paulo \\
\hline A6 & $\begin{array}{l}\text { A Educação Física no } \\
\text { ensino médio: um olhar } \\
\text { sobre o corpo/2015 }\end{array}$ & $\begin{array}{l}\text { Silva, Silva e } \\
\quad \text { Lüdorf }\end{array}$ & Movimento & Rio de Janeiro \\
\hline
\end{tabular}

Fonte: elaboração própria.

Tabela 2 - Síntese dos estudos selecionados, segundo o código de identificação, método, objetivo e principais resultados.

\begin{tabular}{|c|c|c|c|}
\hline Código & Método & Objetivo & Principais resultados \\
\hline A1 & 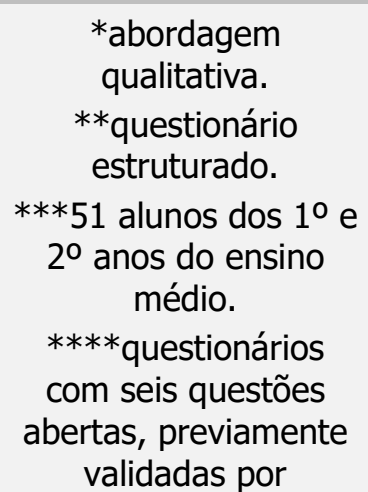 & $\begin{array}{l}\text { Verificar o modo que } \\
\text { assuntos relacionados ao } \\
\text { corpo são abordados por } \\
\text { professores de Educação } \\
\text { Física junto aos alunos do } \\
\text { ensino médio e, até que } \\
\text { ponto a estética corporal } \\
\text { especificamente é uma } \\
\text { preocupação no cotidiano } \\
\text { do corpo discente. }\end{array}$ & $\begin{array}{l}\text { O estudo revelou que } 27 \text { alunos, } \\
\text { afirmaram nunca terem conversado } \\
\text { sobre temáticas que envolviam corpo } \\
\text { com os professores. No entanto, } 19 \\
\text { alunos comentaram que tiveram a } \\
\text { oportunidade de discutir sobre a } \\
\text { temática em trabalhos solicitados pelos } \\
\text { professores, envolvendo temáticas } \\
\text { como: saúde, obesidade, bullying, } \\
\text { dietas radicais e anabolizantes. }\end{array}$ \\
\hline
\end{tabular}




\begin{tabular}{|c|c|c|c|}
\hline A2 & $\begin{array}{c}\text { *abordagem } \\
\text { qualitativa, } \\
\text { exploratória. } \\
\text { **Aplicação de } \\
\text { questionário on-line. } \\
\text { ***70 acadêmicos do } \\
\text { curso de Educação } \\
\text { Física de uma } \\
\text { instituição de Ensino } \\
\text { Superior. } \\
\text { **** instrumento com } \\
\text { perguntas abertas e } \\
\text { fechadas para coleta } \\
\text { de dados. }\end{array}$ & $\begin{array}{l}\text { Investigar as relações } \\
\text { entre as representações } \\
\text { do corpo (preocupação } \\
\text { essencial da Educação } \\
\text { Física) e a cultura } \\
\text { midiática (aspecto } \\
\text { marcante da } \\
\text { contemporaneidade). }\end{array}$ & $\begin{array}{l}\text { Para relacionar corpo e sucesso, foi } \\
\text { apresentado no estudo a seguinte } \\
\text { questão aos acadêmicos: "Você acredita } \\
\text { que a aparência do corpo contribui para } \\
\text { alcançar sucesso?". } 61,4 \% \text { dos } \\
\text { acadêmicos responderam que "sim", } \\
\text { que acreditam que a aparência física é } \\
\text { responsável pelo "sucesso". Outra } \\
\text { questão respondida pelos acadêmicos } \\
\text { foi: "Na sua opinião, o professor de } \\
\text { Educação Física precisa ter um corpo } \\
\text { definido?". Verificou-se que } 51,5 \% \\
\text { responderam que "sim". }\end{array}$ \\
\hline A3 & $\begin{array}{l}\text { * abordagem } \\
\text { quantitativa. } \\
* * \text { Aplicação de } \\
\text { questionário. } * * * 112 \\
\text { alunos dos cursos de } \\
\text { Educação Física. } \\
\text { ***Questionários: } \\
\text { sociodemográfico; } \\
\text { sobre o uso de redes } \\
\text { sociais e o } \\
\text { Sociocultural Attitudes } \\
\text { Towards Appearance } \\
\text { Questionnaire- } 3 \text {. }\end{array}$ & $\begin{array}{l}\text { Investigar a relação entre } \\
\text { o uso das redes sociais, a } \\
\text { influência da mídia e a } \\
\text { imagem corporal de } \\
\text { acadêmicos dos cursos } \\
\text { de Educação Física, de } \\
\text { ambos os sexos. }\end{array}$ & $\begin{array}{l}\text { O estudo realizou a associação entre as } \\
\text { variáveis IMC e a pressão pelo corpo } \\
\text { perfeito, sendo uma correlação } \\
\text { significativa, positiva, mas é uma } \\
\text { associação fraca pelo fato de o Pearson } \\
\text { ser de } 27 \% \text {. As pessoas com IMC mais } \\
\text { alto pontuaram mais no quesito, } \\
\text { pressão pelo corpo perfeito. Outra } \\
\text { associação realizada, expressa-se na } \\
\text { correlação entre o uso das redes sociais } \\
\text { e a pressão pelo corpo perfeito, que } \\
\text { teve uma significância negativa, mas a } \\
\text { associação foi muito fraca, } 17,05 \% \text {. }\end{array}$ \\
\hline A4 & $\begin{array}{l}\text { *pesquisa-ação, de } \\
\text { caráter descritivo. } \\
\text { **Aplicação de } \\
\text { questionário e } \\
\text { observação } \\
\text { participante. } \\
\text { ***turma do } 1^{0} \text { ano B } \\
\text { do Ensino Médio do } \\
\text { turno vespertino } \\
\text { composta por } 25 \\
\text { alunos. }\end{array}$ & $\begin{array}{l}\text { Descrever e refletir a } \\
\text { respeito de uma } \\
\text { experiência pedagógica } \\
\text { na Educação Física, } \\
\text { problematizando a } \\
\text { viabilidade da mídia- } \\
\text { educação no contexto da } \\
\text { Educação Física escolar } \\
\text { com alunos do ensino } \\
\text { médio de uma escola da } \\
\text { rede Estadual de ensino } \\
\text { da cidade de Natal-RN. }\end{array}$ & $\begin{array}{l}\text { Foi questionado aos alunos sobre a } \\
\text { satisfação com seus corpos. Todos, de } \\
\text { forma unânime, responderam que se } \\
\text { encontravam insatisfeitos. Os meninos, } \\
\text { em sua maioria, desejavam ter seus } \\
\text { corpos mais fortes, enquanto as } \\
\text { meninas um corpo mais magro. Ao } \\
\text { realizar uma dinâmica com os } \\
\text { estudantes, utilizando-se de recortes de } \\
\text { revista, foi questionado qual corpo eles } \\
\text { desejavam ter e se este desejo refletia } \\
\text { o corpo que geralmente é exposto pela } \\
\text { mídia. O resultado evidenciou uma } \\
\text { preferência por corpos perfeitos. }\end{array}$ \\
\hline A5 & $\begin{array}{l}\text { *abordagem } \\
\text { qualitativa. } \\
* * \text { entrevistas } \\
\text { semiestruturadas. } \\
\text { ***15 professores de } \\
\text { Educação Física no } \\
\text { ensino médio. } \\
* * * * \text { foi considerada } \\
\text { as visões de Educação } \\
\text { Física escolar } \\
\text { relatadas pelos } \\
\text { professores } \\
\text { entrevistados, } \\
\text { classificando-os em } \\
\text { dois grupos. }\end{array}$ & $\begin{array}{l}\text { Compreender o tipo de } \\
\text { intervenção que os } \\
\text { professores de Educação } \\
\text { Física, realizam em } \\
\text { relação ao fenômeno do } \\
\text { culto ao corpo, e se estes } \\
\text { observam formas de } \\
\text { manifestação dos alunos } \\
\text { de Ensino Médio } \\
\text { relacionadas ao tema. }\end{array}$ & $\begin{array}{l}\text { Ao serem questionados sobre a } \\
\text { influência do culto ao corpo sobre os } \\
\text { alunos do Ensino Médio, alguns } \\
\text { professores afirmaram que eles não } \\
\text { sofrem nenhuma influência e que não } \\
\text { se preocupam com isso. Por outro lado, } \\
\text { a maioria dos professores afirmou notar } \\
\text { alguma influência da tendência do culto } \\
\text { ao corpo, nos alunos do Ensino Médio. } \\
\text { Apenas os professores que se formaram } \\
\text { há cinco anos, ou seja, com menor } \\
\text { tempo de experiência estavam mais } \\
\text { atualizados com relação a essa } \\
\text { temática. }\end{array}$ \\
\hline
\end{tabular}


A valorização da aparência foi destacada no discurso dos docentes, no que se refere às questões estritamente físicas, à aparência ideal e à busca pelo corpo que é considerado belo: [...] se você não tem o corpo que está dentro dos "parâmetros normais" você se sente um pouco rejeitado, diferente, eu acho que existe essa preocupação sim [...].

[...] a questão de estética hoje em dia é muito valorizada; ser bonito, ser "sarado", estar bem, é valorizado até pelos meios de comunicação que impõem isso em nossa sociedade hoje. Eu acho que isso atinge bastante os jovens. (P8)

Legenda: *Método de pesquisa| **Método de coleta de dados| ***Participantes| ****Instrumentos| $\mathrm{P}=$ professor. Fonte: elaboração própria.

$\mathrm{Na}$ totalidade dos 6 artigos, observou-se que o foco principal dos estudos foi discutir sobre a influência da cultura midiática na construção da representação corporal e demais variedades de assuntos referentes ao corpo na contemporaneidade no cenário escolar e universitário. As mídias se conectam nesse contexto, pois permitem conferir as imagens, a ilusão de bem-estar, com possibilidade de projeção de sucesso, de maneira que tanto professores, como alunos reconhecem que as mídias possuem certa influência na disseminação de um ideal de corpo perfeito (BISCARO; SILVA, 2016; SANTOS; GONÇALVES, 2020; CHAVES et al., 2015; COSTA; SILVA, 2014; ASSARITTI; DAOLIO, 2011; SILVA; SILVA; LÜDORF, 2015).

Nos estudos de Chaves et al. (2015) e Costa e Silva (2014), os estudantes, ao serem indagados de como se sentiam em relação ao próprio corpo, sua imensa maioria mostraram-se insatisfeitos. Percebeu-se, por meio de seus discursos, que sua tomada de consciência a respeito de um padrão estético recorrente na mídia influencia a concepção de corpo belo. Essa insatisfação foi mais manifesta pelas meninas do que pelos meninos. O que destaca a necessidade de uma atenção especial dada pelos docentes de Educação Física no que concerne a questões de gênero nesse contexto.

O estudo de Biscaro e Silva (2016), reforça que a noção de corpo forte, magro e perfeito é sustentada especialmente pelo intenso discurso midiático, o que influencia condutas sobre os corpos dos estudantes. Tal fato, reitera a importância dos professores de Educação Física se atentarem para o aprofundamento desses conhecimentos, considerando qual a compreensão dos adolescentes sobre seus próprios corpos e como estas concepções influenciam suas práticas corporais dentro e fora da sala de aula.

A fim de refletir sobre a influência midiática e diante de toda problematização já construída, uma categoria que emergiu nas respostas dos professores, nos estudos de Costa e Silva (2014) e Assaritti e Daolio (2011), foi o corpo biológico. Para os professores, a temática se configura pela compreensão de corpo apenas no sentido de um organismo, por seu aspecto biológico que as aulas se dão através de práticas voltadas ao esporte. No qual a qualidade de vida está relacionada apenas com a ausência de doenças, não considerando o bem-estar social. 
No estudo de Silva, Silva e Lüdorf (2015), por sua vez, os professores, ao serem indagados a respeito da existência de oportunidades para discussões relacionadas ao corpo com seus alunos do ensino médio, afirmaram, com raríssimas exceções, não fazer desses momentos uma prática atrelada ao planejamento do curso. Ao contrário, as discussões ocorrem apenas quando surgem situações no cotidiano das aulas, derivadas de assuntos levantados pela mídia, tais como anorexia, uso de anabolizantes, algum tipo de manifestação de insatisfação corporal ou dúvidas gerais envolvidas com a Educação Física.

\section{DISCUSSÃO}

Nos últimos anos, houve uma reconfiguração de padrões corporais por meio da influência direta da cultura midiática na construção da representação do corpo moderno (BISCARO; SILVA, 2016). Castro et al. (2016), ratificam essa informação ao apontar que a mídia ressalta os padrões de beleza a serem seguidos e os benefícios estéticos adquiridos pelo cuidado com o corpo, de forma que os indivíduos com uma imagem idealizada de juventude, boa forma física e beleza possuem um valor econômico de troca mais elevado.

Cabe frisar que o culto à magreza, disseminado pelas mídias, atinge especialmente as mulheres, no qual o desprezo à possibilidade de engordar revela significações muito presentes na sociedade contemporânea (THEBALDI, 2020). Dessa maneira, a magreza é tomada como sinônimo de moderação, domínio de si, sucesso e adaptação social; ao contrário, a gordura, a obesidade, é percebida como um fracasso moral, uma incapacidade de se controlar, uma indisciplina (CASTRO et al., 2016).

Neste contexto, a escola insere-se, enquanto instituição social que não está imune a tais concepções, incorporando práticas que suscitam a crítica com fundo ideológico e pela dominação, que contribuem para sedimentar a visão do corpo como uma superfície de inscrição de eventos, práticas e relações de poder, capazes de mostrar novos caminhos de ressignificação do corpo nos espaços sociais (AZEVEDO; GONÇALVES, 2007).

Entretanto, o problema maior surge quando, no lugar de promover o diálogo, de aproximar-se do cotidiano do aluno, a Educação apenas passe a reproduzir o discurso da mídia, reforçando estereótipos, discursos, modos de ser e de viver, não estimulando uma reflexão crítica sobre o que entra prelos olhos e ouvidos desses jovens (MEZZAROBA, 2020; SANTOS JUNIOR, 2012). A enorme influência exercida pela mídia faz dela uma formadora de opiniões agindo sobre a autonomia desses jovens.

Azevedo e Gonçalves (2007) destacam que a Educação Física enquanto componente curricular, confere, hoje, significados contemporâneos ao corpo, devido a influências inavegáveis, especialmente, da sociedade no ambiente escolar. Diante disso, a Educação Física escolar deve constituir-se, primordialmente, em um espaço para oportunizar aos alunos à compreensão, à crítica e o questionamento desse momento de idolatria à imagem narcísea do corpo, que é veiculada pela mídia.

O entendimento de corpo restrito somente aos aspectos biológicos, fato muito evidente na prática pedagógica dos professores de Educação Física, deve ser atendido em sua plenitude, através das ciências biológicas, humanas e sociais (SILVA; SANTOS; MEZZAROBA, 2013). Assim, o pressuposto é que as representações presentes, sejam alimentadas ou questionadas, durante a formação inicial 
dos professores, o que pode contribuir para a continuidade ou melhoria das práticas pedagógicas efetivamente concretizadas na Educação Básica e Superior (BISCARO; SILVA, 2016).

Nesse sentido, é necessário introduzir e integrar o aluno na cultura corporal de movimento, além dos conhecimentos somente esportivos. A título de exemplo, é possível destacar algumas das temáticas importantes presentes no cotidiano de jovens estudantes, de acordo com as Orientações Curriculares para o Ensino Médio (BRASIL, 2006): o corpo no mundo dos símbolos e como produção da cultura; o corpo no mundo da produção estética; e construção cultural das ideias de beleza e saúde. Pode-se inferir, por meio desse documento, que cada um desses conteúdos possui uma vinculação social com a realidade atual.

Os professores descrevem as preocupações e as características que veem no perfil dos alunos do Ensino Médio, mas não se aprofundam nas razões deles se preocuparem com o corpo, com o físico, com a aparência (ASSARITTI; DAÓLIO, 2011). Esse fato revela que existem muitos pontos que precisam ser repensados, na prática, da Educação Física Escolar para que ela consiga dar conta de refletir sobre esse fenômeno, e construir junto aos alunos um contraponto às mensagens que vêm dos meios de comunicação de massa (GUEDES JUNIOR, 2020).

Cabe citar um dos estudos apresentados nessa RIL, realizado por Assaritti e Daólio (2011), que revelou que a maioria dos professores possuía uma visão mais voltada para o aprendizado das modalidades esportivas nos moldes do esporte profissional, ou seja, uma visão mais tecnicista da área. Para Biscaro e Silva (2016) a prática dos conteúdos pedagógicos apresentados atualmente pelos professores tem um fim em si mesmo, é a prática pela prática, que não abre espaço para problematizações nem reflexões a respeito do culto ao corpo disseminado pela mídia, ou assuntos análogos. Alguns professores empenham-se em estudar tais assuntos para introduzi-los nas suas aulas, contudo encontram dificuldades para se atualizarem devido ao grande número de aulas e o pouco estímulo ao estudo pelas instituições de ensino (ASSARITTI; DAOLIO, 2011).

No entanto, é possível ampliar as discussões acerca dos discursos da mídia sobre as práticas corporais no âmbito escolar, por intermédio da incorporação de práticas pedagógicas em mídia-educação. Dessa maneira, a construção de novas possibilidades para a Educação Física escolar e a carência de ampliação dessas intervenções, corrobora para um novo fazer pedagógico, trazendo alternativas para se questionar o macrodiscurso do poder da beleza e da aparência propagado pela mídia (COSTA; SILVA, 2014; CHAVES et al. 2015).

\section{CONSIDERAÇÕES FINAIS}

Após leitura minuciosa, levantamento e análise dos dados dos artigos, observou-se a importância dada ao corpo, puramente no aspecto biológico e estético por parte dos professores de Educação Física, além da carência de maiores debates a respeito de assuntos a respeito ao atual culto ao corpo. Estas discussões são demandadas na sociedade contemporânea, sendo essencial que os docentes abram espaço para problematizá-las, fomentando assim, o pensamento crítico de seus alunos, que são os principais alvos da cultura dos corpos evidenciada pela mídia.

Nesse sentido, é importante que os professores em suas aulas de Educação Física reflitam até que ponto a influência midiática é saudável, pois no que concerne à busca excessiva pelo corpo sarado, magro e perfeito, os jovens podem se submeter a sacrifícios corporais que causam malefícios à sua saúde. A Educação Física deve desenvolver a autonomia corporal dos alunos, ressignificando a prática 
das atividades desenvolvidas, além de oferecer uma reflexão sobre a possível insatisfação por parte deles diante de seus corpos.

Ressaltamos que cabe ao professor de Educação Física estimular uma relação crítica entre a mídia e os alunos, para que aos poucos eles desenvolvam autonomia nas suas opiniões. A Educação é fundamental nesse ínterim, pois é a partir dela que os estudantes podem obter um olhar mais ampliado dos discursos veiculados pelas mídias. Sendo destacado ainda, a necessidade de uma formação inicial dos professores, que possa contribuir para a continuidade ou melhoria das práticas pedagógicas para que o professor possa instigar sobre esse fenômeno em seus alunos.

Esta pesquisa possui limitações relacionadas ao método adotado, por se tratar de uma revisão do tipo integrativa, o estudo apenas mostra um retrato do estado da arte atual, não sendo possível avaliar intervenções educativas realizadas pelos professores de Educação Física em sala de aula sobre mídia e culto ao corpo. Além disso, uma limitação relaciona-se ao foco do estudo ser somente da área de Educação Física, sendo que a maioria dos estudos abrange diversas áreas de conhecimento. Ademais, a maioria dos estudos identificados tende a investigar o uso das mídias em sala de aula e não focado sobre o atual culto ao corpo, a supervalorização da aparência disseminada nas mídias ou, algum assunto similar.

Finalmente, esta revisão concretiza a necessidade de novos estudos que busquem verificar a opinião dos docentes sobre a abordagem de questões relacionadas ao corpo contemporâneo em suas práticas e, também, a comparação de opiniões de alunos da Educação Básica e Superior a respeito da estética corporal e a consequência da mesma em suas vidas.

Dessa forma, sugere-se para trabalhos futuros, pensar na responsabilidade interventora e articuladora, do discurso midiático que devem ser abordados nas propostas curriculares para diferentes modalidades de ensino, através do plano e planejamento de novas práticas pedagógicas e metodologias de ensino utilizadas pelos professores de Educação Física. Assim, espera-se que, essa revisão, possa contribuir com a área da Educação, bem como estimular novos caminhos e alternativas de investigação sobre a temática.

\section{REFERÊNCIAS}

ARAÚJO, Regina Magna Bonifácio; SILVA, Marcelo Donizete da; SILVA, Marilene do Carmo. A formação continuada de professores da educação básica: concepções e desafios na perspectiva dos docentes. Revista @mbienteeducação, v. 12, n. 3, p. 17-38, set./dez. 2019.

ASSARITTI, Dolores Setuval; DAOLIO, Jocimar. A intervenção do professor de educação física junto a alunos do ensino médio sobre o fenômeno do culto ao corpo. Conexões, v. 9, n. 1, p. 67-91, jan./abr. 2011.

AZEVEDO, Aldo Antonio de; GONÇALVES, Andréia Santos. Reflexões acerca do papel da resignificação do corpo pela educação física escolar, face ao estereótipo de corpo ideal construído na contemporaneidade. Conexões, v. 5, n. 1, p. 67-85, 2007.

BISCARO, Marlene Vitória; SILVA, Fábio Luiz da. Corpo, mídia e Educação Física. Revista educação pública, v. 1, n. 1, p. 1-3, 2016. 
BRASIL. Base Nacional Comum Curricular (BNCC). Educação é a Base. Brasília, MEC/CONSED/UNDIME. [online] Disponível em: http://basenacionalcomum.mec.gov.br/. Acesso em: 12 jun. 2020.

BRASIL. Resolução CNE/CES n 6, de 18 de dezembro de 2018. [online] Disponível em: https://www.semesp.org.br/wp-content/uploads/2018/12/RESOLU\%C3\%87\%C3\%830-CNE_CESN\%C2\%BA-6-DE-18-DE-DEZEMBRO-DE-2018.pdf. Acesso em: 15 jun. 2020.

BRASIL. Orientações curriculares para o ensino médio: linguagens, códigos e suas Tecnologias. [online]

Disponível

em: http://portal.mec.gov.br/seb/arquivos/pdf/book_volume_01_internet.pdf. Acesso em: 11 jun. 2020.

BROOME, Marion English. Integrative literature reviews for the development of concepts. In: RODGERS, Beth; KNAFL, Kathleen, editors. Concept development in nursing: foundations, techniques and applications. Philadelphia (USA): W.B Saunders Company, 2000.

CASTRO, Juliana Brandão Pinto de. et al. Alimentação, corpo e subjetividades na educação física e na nutrição: o ranço da adiposidade e a ascensão dos músculos. DEMETRA: Alimentação, Nutrição \& Saúde, v. 11, n. 3, p. 803-824, 2016.

CHAVES, Paula Nunes. et al. Construindo diálogos entre a mídia-educação e a Educação Física: uma experiência na escola. Motrivivência, v. 27, n. 44, p. 150-163, maio 2015.

COSTA, Naiana Thaíssa Menezes; SILVA, Alan Camargo Corpo e Educação Física Escolar no ensino médio: a visão dos alunos. Revista Brasileira de Ciências do Esporte - RBCE, v. 36, 2, supl., p. 223-237, abr./jun. 2014.

DIONISIO, Ângela Paiva. Gêneros multimodais e multiletramento. In: KARWOSKI, Acir Mario; GAYDECZKA, Beatriz; BRITO, Karim Siebeneicher. (Orgs.). Gêneros textuais: reflexões e ensino. Palmas e união da Vitoria, PR: Kaygangue, 2005.

FANTIN, Monica. Contextos, perspectivas e desafios da mídia-educação no Brasil. In: ILANA, Eleá. (Org.). Agentes e vozes: um panorama da mídia-educação no Brasil, Portugal e Espanha. 1ed.Götenburg: Nordicon, 2014, v. 1, p. 49-57.

GALVÃO, Taís Freire; PEREIRA, Mauricio Gomes. Revisões sistemáticas da literatura: passos para sua elaboração. Epidemiologia e Serviços de Saúde, v. 23, n. 1, p. 183-184, jan./mar. 2014.

GIL, Antonio Carlos. Métodos e técnicas de pesquisa social. 5.ed. São Paulo: Atlas, 2008.

GUEDES JUNIOR, Dilmar Pinto. Mídia social, marketing pessoal e novas tendências do fitness, mas não se esqueçam das evidências científicas. Revista Brasileira de Fisiologia do Exercício, v. 18, n. 4, p. 179, 2020.

MEZZAROBA, Cristiano. A mídia, as tecnologias e a educação física no Brasil: uma descrição genealógica. Revista Tempos e Espaços em Educação, v. 13, n. 32, p. 1-23, jan./dez. 2020.

SANTOS JUNIOR, Nei Jorge Santos. Eles compreendem de outro jeito: mídia, educação física escolar e possibilidades. Arquivos em Movimento, v. 8, n. 2, p. 65-78, jul./dez. 2012.

SANTOS, Andreia Mendes dos; COSTA, Fábio Soares da. Filosofia da Corporeidade: transversalizações de um corpo intenso de devir. Educação \& Realidade, v. 43, n. 1, p. 223-237, jan./mar. 2018. 
SANTOS, Mariany Silva; GONÇALVES, Vivianne Oliveira. Uso das redes sociais, imagem corporal e influência da mídia em acadêmicos dos cursos de educação física. Itinerarius Reflectionis, v. 16, n. 3, p. 1-18, 2020.

SIQUEIRA, Alexandra Bujokas de. Mídia-educação a serviço da cidadania: uma proposta para a formação de assistentes sociais. In MACEDO, Alessandra Xavier Nunes; PIRES, David Ulisses Brasil Simões; ANJOS, Fernanda Alves (org.) Educação para a Mídia - Cadernos de Debate da Classificação Indicativa. Brasília: Ministério da Justiça/ Secretaria Nacional de Justiça, 2014.

SILVA, Markus de Lima; SANTOS, Valdione Evangelista Alves; MEZZAROBA, Cristiano. A compreensão de alunos do ensino fundamental de uma escola pública sobre saúde, corpo e mídia a partir da telenovela "malhação". Caderno de Educação Física e Esporte, v. 10, n. 19, p. 43-54, 2013.

SILVA, Fernanda Azevedo Gomes da; SILVA, Luis Aureliano Imbiriba e; LÜDORF, Silvia Maria Agatti. A educação física no ensino médio: um olhar sobre o corpo. Movimento (ESEFID/UFRGS), v. 21, n. 3, p. 673-685, jul./set. 2015.

SOUZA, M. T. et al. Revisão integrativa: o que é e como fazer. Einstein (São Paulo), v. 8, n. 1, p. 102-106, jan./mar. 2010.

THEBALDI, Bruno. Os integrados e os outsiders da aparência: o "belo" e o "feio" em tempos de "culto ao corpo". Parágrafo, v. 7, n. 1, p. 66-84, jan./jun. 2020.

Submissão: 9/11/2020

Aceito: 18/01/2021 